\title{
Correction to: Impact of Spring AAO on Summertime \\ Precipitation in the North China Part: Observational Analysis
}

\section{Zhengxuan Yuan ${ }^{1}$ • Jun Qin ${ }^{1}$ - Shuanglin $\mathrm{Li}^{1} \cdot$ Sijing Huang ${ }^{1} \cdot$ Yassin Mbululo ${ }^{1,2}$}

Published online: 23 January 2020

(C) Korean Meteorological Society and Springer Nature B.V. 2020

\section{Correction to: Asia-Pacific J Atmos Sci}

$$
\text { https://doi.org/10.1007/s13143-019-00157-2 }
$$

The original version of this article unfortunately contains some mistakes.

(1) In page 4, the description text for Fig. 6, the sentence 'Figure 6a to e show the leading MCA mode between JA Antarctic sea ice concentration (JA-ASIC) and 700 hPa-GPH (H700) south of $20^{\circ} \mathrm{S}$ ' should be replaced by 'Figure 6a to e show the leading MCA mode between March $700 \mathrm{hPa}-\mathrm{GPH}(\mathrm{M}-\mathrm{H} 700)$ south of $20^{\circ} \mathrm{S}$ and Antarctic sea ice concentration (ASIC)'.

(2) In page 5, the description text for Fig. 6, the sentence 'Each title of figures contains the name of each pattern, $\mathrm{CF}$ value and correlation coefficient between two time series of each pattern (CR).', and two words 'JA-' and 'and CR' in this paragraph should be deleted for their redundant.

(3) In page 6, the caption of Fig. 6, 'JA-ASIC and H700' should be replaced by 'M-H700 and ASIC' and 'JAASIC' at the end of the first sentence should be replaced by 'ASIC'.

The online version of the original article can be found at https://doi.org/ 10.1007/s13143-019-00157-2

Jun Qin

qinjun@cug.edu.cn

School of environmental studies, China University of Geosciences (Wuhan), Hubei 430074, China

2 Department of Geography and Environmental Studies, Sokoine University of Agriculture, Morogoro, Tanzania 